\title{
Avoiding the sharp tongue: Anticipated written messages promote fair economic exchange
}

\author{
Erte Xiao \\ DEPARTMENT OF SOCIAL AND DECISION SCIENCES \\ CARNEGIE MELLON UNIVERSITY \\ EXIAO@ANDREW.CMU.EDU \\ Daniel Houser \\ INTERDISCIPLINARY CENTER FOR ECONOMIC SCIENCE \& DEPARTMENT OF ECONOMICS \\ GEORGE MASON UNIVERSITY \\ DHOUSER@GMU.EDU
}

\begin{abstract}
Research in economics and psychology has established that informal nonmonetary sanctions, particularly expressions of negative emotion or disapproval, can enforce fair economic exchange. However, scholars are only beginning to understand the reasons non-monetary sanctions affect economic outcomes. Here we provide evidence that a preference to avoid written expression of disapproval, or negative emotion, plays an important role in promoting fair decision making. We study one-shot Dictator games where one subject has the right to determine a division of an amount of money between herself and her receiver. In relation to the standard game, we find significantly fewer earning-maximizing decisions when receivers can react to offers with ex post written messages. We further find that credible threats of monetary sanctions, while economically inefficient, are significantly more effective than written messages in deterring selfishness. Our data provide new perspectives on the role of communication in promoting economic efficiency in social environments, and support economic theories of decision incorporating psychological factors such as guilt, shame, and self-deception.
\end{abstract}

\section{*Correspondent: exiao@andrew.cmu.edu}

Acknowledgements: Helpful comments on this project were provided by Armin Falk, Felix Marklein, participants in seminars at the University of Pennsylvania, the University of Texas at Dallas, and attendees of the 2005 Behavioral Economics Summer School at the Central European University, the Fifth Annual Biology and Philosophy Conference at Duke University, the International Meetings of the Economic Science Association and the Southern Economic Association. 


\section{Introduction}

Economic theorists increasingly emphasize the role of fairness in directing decisions (see, e.g., Bolton and Ockenfels, 2000; Fehr and Schmidt, 2002; Fehr, Gächter and Kirchsteiger, 1997) and the corresponding importance of monetary sanctions in promoting pro-social behaviors (see, e.g., Ostrom et al., 1992; Yamagishi, 1986, 1988; Fehr and Gächter, 2000; Andreoni et al., 2003; Dickinson, 2001). Recently, an experimental literature has documented the importance of informal nonmonetary sanctions, particularly expressions of negative emotions or disapproval, in enforcing norms and promoting cooperation and fairness (see, e.g., Gächter and Fehr, 1999; Rege and Telle, 2004; Masclet et al., 2003; Noussair and Tucker, 2005). Reasons for this effect, however, are only beginning to be understood. One question is whether disapproval effects are anticipatory. The answer is important because, if people try to avoid disapproval, mechanisms can be designed to discourage norm violations even during oneshot anonymous exchange (e.g., online auction sites.) Here we offer new evidence that anticipated written reactions promote fair economic exchange, though somewhat less effectively than anticipated monetary sanctions.

Previous empirical results on this topic are inconclusive (Gächter and Fehr,1999.) One reason is that laboratory studies on this issue have generally used repeated games so that disapproval effects are due to unknown combinations of factors including communication, reactions to disapproval, and attempts to avoid disapproval (Masclet et al., 2003). Indeed, communication and reaction require repeat interaction to encourage norm obedience effectively, as has been well-demonstrated in laboratory research (see, e.g., Miller et al., 2002; Masclet et al., 2003 ; Noussair and Masclet, 2005.) However, these results do not inform the role of disapproval avoidance in social norm enforcement ${ }^{1}$.

It is natural that attempts to avoid expressions of disapproval can have consequences for economic exchange. An individual who wants to selfishly maximize

\footnotetext{
${ }^{1}$ For example, Rege and Telle (2004) compare decisions in standard one-shot public goods games with anonymous contributions to otherwise identical games where subjects' contribution decisions are made sequentially and in view of all other participants. They find contributions are higher in the latter condition, consistent with disapproval avoidance (or approval seeking.) However, because contributions were sequential their data can also be explained by reciprocity and conditional cooperation (Kurzban and Houser, 2005), herding (Ferraro and Vossler, 2005) or because subjects come to an improved understanding of the game's incentives (Andreoni, 1995; Houser and Kurzban, 2002).
} 
earnings might also expect to feel guilt or shame if they do so $^{2}$. Cognitive dissonance theory (see, e.g., Festinger, 1957; Tesser and Achee 1994; Aronson, 1995; Akerlof and Dickens, 1982; Rabin, 1994; and Konow, 2000), posits that people experience an unpleasant "tension" stemming from these opposite motivations (a desire to maximize earnings vs. a belief in fairness). One strategy to reduce this tension is to self-deceive by manipulating one's own beliefs in such a way that guilt or shame is reduced and selfishness supported. For example, one could choose to believe that if the situations were reversed one's counterpart would also make a selfish decision. However, if one's counterpart is able to express disapproval then it is more difficult to manipulate one's own beliefs in this way. The reason is that dictators are led to consider all the possible reactions receivers might have to dictators' decisions. In particular, dictators will recognize the possibility of being confronted with a disapproving message inconsistent with their self-serving beliefs. The effect of disapproval avoidance on behavior stems from the belief that more selfish decisions are more likely to be met with disapproval.

Note that cognitive dissonance theory leaves little room for individuals to avoid guilt or shame, and rescue a belief manipulation strategy, by committing ex ante not to observe a counterpart's ex post emotion expression. The reason is that a decision not to observe a freely observable message suggests a belief that one's counterpart might be unsatisfied with the exchange; but such a belief is inconsistent with self-deception ${ }^{3}$.

Our principal hypothesis is that ex post messaging opportunities enable people to express their feelings of disapproval and therefore can promote fair economic outcomes.

\footnotetext{
${ }^{2}$ Differences between shame and guilt have long been studied in psychology yet still remain controversial (see, e.g., Kandel and Lazear, 1992; Elster, 1996, 1998,1999; Batson 1991; Shavell, 2002, or Tangney et al., 2007 for a review). It is, however, well accepted that shame and guilt are intrinsic non-material costs associated with unfair behavior (see, e.g., Baumeister, et al., 1994). Also, these emotions have been used in a significant amount of recent economic theory (see, e.g., Charness and Dufwenberg, 2006; Dufwenberg, 2002; Jacob and Charles, 2000; Kandel and Lazear, 1992; Bowles and Gintis, 2001 and Andreoni, 1990). ${ }^{3}$ Avoiding messages written by receivers is quite different than avoiding knowing the final amount the receiver earns, as studied in Dana, Weber and Kuang (2007). Their paper provides experimental evidence that a significant number of dictators prefer not to reveal whether their choices hurt or help their respective receivers. The key is that, because the receivers do not know if their respective dictators know receiver's earnings, dictators who make a selfish choice can appear to be fair both in their own eyes as well as in the eyes of their receivers. In our study, however, dictators know that choosing more entails that receivers earn less, and receivers know that dictators know this is the case. Therefore, it is natural for the dictators to expect a receiver, in his message, to comment on his perception of his dictator's fairness. Choosing to avoid viewing a message cannot change a receiver's perception of a dictator's decision.
} 
Moreover, this can be true in one-shot anonymous exchange, and need not require that the messages be read.

We report data from one-shot dictator games that provide clean evidence on this hypothesis. We compare decisions in a standard dictator game to decisions in otherwise identical games where, after dictators complete their decisions, receivers have an opportunity (but not a requirement) to write a message to their respective dictators. Our design rules out bilateral communication or negotiation, leaving avoidance as the only plausible source of behavioral differences. In addition, we compare efficacy between monetary and non-monetary punishment threats. Using data from Xiao and Houser (2005), we compare amounts sent in our dictator game with receiver message opportunities to amounts offered by proposers in otherwise identical ultimatum games that include threats of costly monetary punishment.

We find that, in relation to standard dictator games, profit-maximizing divisions are less frequent when receivers have ex post opportunities to provide written responses. On the other hand, the frequency of earnings-maximizing offers remains higher than found in standard ultimatum games. It follows that opportunities for (zero cost) ex post emotion expression can promote fairness, but perhaps less effectively than threats of severe (but costly and inefficient) monetary sanctions.

Our results complement Xiao and Houser's (2005) finding that people facing unfair economic exchange often substitute emotion expression for relatively more costly material punishment. Notably, this is true even when doing so cannot affect final allocations. Taken together with data reported here, we conclude that providing opportunities in markets for ex post emotion expression can promote efficient exchange and increase social welfare by reducing both costly punishment activity as well as selfish decisions. In addition, these efficiency gains do not require repeated interactions.

Part of our paper is closely related to Ellingsen and Johannesson (2008), who also study non-monetary sanctions using dictator games and also find anticipated feedback from receivers promotes dictator fairness. As they point out, however, our designs differ and our conclusions are not identical (see p. 103 of their paper). One design difference is that, unlike our study, Ellingsen and Johannesson (2008) place no restrictions on the nature of receiver feedback. We discuss below that this might help to explain differences 
between our and respective results. In addition, unlike their design, we do not require dictators to read messages. Consequently, in areas where our studies overlap, our data both support and extend their findings. At the same time, our paper is distinct from Ellingsen and Johannesson (2008) in that we are able to draw inferences regarding the relative efficacies of monetary and non-monetary sanctions.

Section II describes the design of our experiment. Related theory is presented in Section III. Results appear in Section IV and Section V concludes.

\section{Experiment}

\section{II.A. Ultimatum Game with Emotion Expression}

The current paper reports data from new experiments but also incorporates data from Xiao and Houser (2005), and we begin this section with brief comments on that paper. Xiao and Houser (2005) study links between individuals' desires for emotion expression and costly punishment decisions. They hypothesize that responders in an ultimatum game are less likely to use costly punishment (reject offers) when their feelings about unfair offers can be conveyed to their respective proposers in an alternative and less costly way. To test this they conducted two treatments with the ultimatum game- no emotion expression (NEE) and emotion expression (EE). NEE is the standard ultimatum game (see, Güth et al, 1982) where the proposer and the responder are given \$20 to split. The proposer decides how many cents out of each dollar to keep, and the responder decides whether to accept the offer (divide \$20), or to reject the offer (divide $\$ 0$ ).

The EE treatment is identical, except that after a responder observes her proposer's decision she is given an opportunity, not a requirement, to write a message to her proposer at no pecuniary cost. Any message is delivered to her proposer concurrently with her accept or reject decision.

Xiao and Houser (2005) find support for their hypothesis. First, $87 \%$ of all responders wrote a message. Furthermore, rejection rates of unfair offers ( $20 \%$ of the surplus or less) were statistically significantly lower in the EE than NEE treatment. Interestingly, Xiao and Houser (2005) find no significant difference in offer distributions between the EE and NEE treatments. However, this does not rule out the possibility that opportunities for ex post emotion expression might affect fair exchange. The reason is 
that proposers in both the NEE and EE treatments faced threats of monetary punishment (rejections), and such threats might mask an underlying non-monetary sanction effect.

\section{II.B. Dictator Games with Emotion Expression}

Our new data is based on dictator games with and without receiver emotion expression. Our experiment consists of two treatments: a standard dictator game without emotion expression (DNEE) and a dictator game with emotion expression (DEE). In the DNEE treatment, two subjects are randomly paired, one as dictator (divider in the instructions) and the other as receiver (counterpart in the instructions). The dictator decides how much of $\$ 20$ s/he wants to send to the receiver and the receiver earns that amount. The amount sent can be interpreted as a measure of fairness, because there are no other consequences associated with dictators' decisions.

The DEE treatment is identical to DNEE except that, after dictators make their decisions, receivers have an opportunity to write messages to their respective dictators. Our hypothesis is that opportunities for ex post emotion expression lead to relatively less selfish offers in this case than in the DNEE treatment. Note that this hypothesis relates entirely to dictators' decisions. In particular, unlike Xiao and Houser (2005), the emotional nature of any message does not directly bear on our hypothesis as dictators make their decision before receiving the message.

It is important to note that, in order to make our results comparable to Xiao and Houser (2005), we adopt the same action space used in the ultimatum game reported there. In particular, dictators can send 2, 4, 8, 10, 12, 16 or 18 (out of 20) dollars to their

respective receivers. In view of our motivating hypothesis, we do not require dictators to read messages. In addition, following the emotion expression treatment in Xiao and Houser (2005), foul language is not allowed. As we discuss further in section V, this design feature works against our hypothesis that ex post opportunities for emotion expression promote fairness. Finally, although dictators were told that they would see the messages, we did not indicate that they were required to read any message they received. 


\section{II.C. Procedures}

Experiments included undergraduate students recruited from the general student population at George Mason University, using standard procedures in place at the Interdisciplinary Center for Economic Science. We ran nine sessions. Subjects were randomly and separately assigned to two rooms: one for dictators and the other for receivers. Each subject was randomly assigned a letter as his or her ID for the duration of the experiment. A receiver and a dictator were paired if they held the same letter. All subjects received an instruction sheet explaining the rules of the game. After reading the instructions each subject was required to complete a quiz to verify comprehension. The game started after every subject successfully finished the quiz.

The games proceeded as follows. First, dictators indicated the split on a decision sheet. After all dictators had finished, the experimenter took all the decision cards to the receivers' room and gave each receiver his or her dictator's decision card. Subjects were given pen and paper in both treatments. After observing the dictator's decision, the receiver returned the decision card to the experimenter. In the DEE treatment, each receiver was given a card for writing a message to his/her dictator. This card was distributed immediately prior to distributing the dictator's decision card. Receivers were asked to avoid indecent language, but were otherwise given no guidance regarding what, or whether, to write. When receivers had finished, the message and decision cards were returned to the experimenter. The experimenter then delivered the decision cards (and message cards in the DEE treatment) to the dictators. In the DEE treatment, we delivered the decision cards to the dictators, and dictators decided on their own whether to read the messages.

Each subject played the game exactly once. In both treatments subjects were given as much time as they liked to make their decisions. Subjects were paid privately with cash at the end of the experiment. Each subject received a $\$ 5$ show up bonus in addition to money earned in the game ( $\$ 10$ on average, of course $)^{4}$. Subjects were in the lab about 45 minutes.

\footnotetext{
${ }^{4}$ Severn sessions were run in 2004 and we ran another two sessions (one DEE treatment and one DNEE treatment) in 2007. ICES show-up bonuses for all laboratory experiments increased in 2007 to $\$ 7$, and we used that amount for our 2007 experiments as well.
} 
We conducted a message evaluation session after all of the dictator game sessions had been completed. We recruited ten message evaluators from the general undergraduate population at George Mason University. Potential evaluators were excluded if they had previously participated in any ultimatum game, or the message evaluation experiment in the Xiao and Houser (2005), or any dictator game experiment. Evaluators were given a receiver's instructions because some messages were not comprehensible absent this context. After reading the instructions evaluators were given a randomly ordered list of messages. Evaluators classified each message as "positive", "negative" or "neutral" in emotional content. Evaluators were paid \$10 if they classified every message and an additional $\$ 5$ if their message classification agreed with the most popular classification for each of two randomly chosen messages ${ }^{5}$. Evaluators were in the laboratory for about an hour, and median earnings were $\$ 15$. We classified messages according to the most popular evaluator classification. There was a single most popular classification in 33 of 35 cases. The two ties were broken by the investigators' own evaluations.

\section{Theory}

Standard economic theory assuming self-interested earnings maximization predicts dictators in the DNEE treatment will give the minimum amount, as receivers have no bargaining power. The same is predicted in the DEE treatment, as ex post messages cannot affect earnings. Substantial evidence of non-selfish behavior has been observed over decades of experiments, and one way to explain this is to build social preferences into theory. This section points to recent contributions in this spirit, and their predictions regarding dictator decisions in our experiment.

\section{A. Rabin (1993), Fehr and Schmidt (1999) and Bolton and Ockenfels (2000)} Using the "psychological game" framework first introduced by Geanakoplos, Pearce and Stacchetti (1989), in which utility depends on players' beliefs, Rabin (1993) develops a game-theoretic model that incorporates preferences for fairness. In Rabin's model, an individual makes her decision based on both her own material payoff and her beliefs

\footnotetext{
${ }^{5}$ The 26 messages in 2004 experiment and 9 messages in 2007 experiment were evaluated separately with the same procedure except the evaluators in 2007 were paid $\$ 5$ for finishing all the classifications and earned a $\$ 7$ show-up bonus.
} 
about her counterpart's intentions. Rabin's model predicts dictators will behave the same way in both the DNEE and DEE treatments. The reason is that, in both treatments, receivers and can neither signal intentions nor change dictators' beliefs prior to dictators' decisions.

The models of Fehr and Schmidt (1999) and Bolton and Ockenfels (2000) assume an individual's utility depends only on their own and others' earnings. Because ex post message opportunities cannot affect earnings, these models predict that dictators will behave the same way in both the DNEE and DEE treatments.

\section{B. Konow (2000)}

Konow develops a model of cognitive dissonance (see also Rabin, 1994; Akerlof and Dickens 1982). As we noted above, individuals suffer from cognitive dissonance when they have selfish preferences but believe in fairness. If a dictator could choose any belief, then she could choose to believe it is fair for her to behave selfishly. However, beliefs are not absolutely pliable, and Konow assumes there are costs to holding beliefs that differ from a reasonable view of what is fair (e.g., costs of searching for justifying arguments). Hence, Konow's model predicts that higher costs of self-deception reduce selfishness.

In the standard dictator game it is easy for dictators to choose beliefs that support selfishness (e.g., the belief that they are doing to their counterpart what their counterpart would have done to them.). In the emotion expression treatment the possibility of receiving messages of disapproval makes it difficult to self-deceive. Thus, Konow's model predicts relatively more generous offers to receivers in the DEE treatment ${ }^{6,7}$.

\section{Results}

We obtained observations on 140 undergraduates: 34 pairs of subjects in the DNEE treatment and 36 pairs in the DEE treatment. Table 1 gives summary statistics for

\footnotetext{
${ }^{6}$ This result follows immediately from Konow (2000) under the assumption that the cost of searching for self-serving arguments increases when one's counterpart can send an ex post message.

${ }^{7}$ In a related contribution, Charness and Dufwenberg (2006) develop a model of guilt aversion (see also Huang and Wu (1994) and Dufwenberg (2000)). The key assumption in Charness and Dufwenberg (2006) is that people experience guilt, so disutility, when they believe they have failed to meet their counterparts' expectations. They consider cases where counterparts' expectations are known prior to decisions, while in our experiment expectations are made clear at best ex post. Hence, it is not obvious how to take their model to our experiment's data.
} 
decisions in these games, as well as our earlier ultimatum games that use the same action space. Visual inspection reveals the following general patterns. Mean offers increase with emotion expression opportunities, and are larger in ultimatum than dictator games ${ }^{8}$. Frequencies of equal-split offers are not very different among treatments (and there are no statistically significantly differences), although frequencies of unfair 90/10 offers are much higher in the baseline dictator game than in any of the three other treatments.

Our analysis below focuses on changes in 90/10 decisions. We begin by comparing dictators' decisions in games with and without emotion expression, providing clean evidence on the impact of emotion expression on fairness. Next, we compare dictators' decisions in the DEE treatment to proposers' decisions in Xiao and Houser (2005)'s NEE treatment. This offers evidence on the relative efficacies of both threats of emotion expression and threats of rejection in promoting fairness. Finally, we discuss receivers' messages.

\section{IV.A. Emotion Expression and Fair Divisions}

Figure 1 describes the distribution of dictators' offers in each treatment. In both treatments, about half of the dictators offer $40 \%$ or more to the receiver and the other half offer $20 \%$ or less. We define offers of $40 \%$ or more as fair and $20 \%$ or less as unfair. The distribution of fair offers is similar in the DNEE and DEE treatments. In both treatments, about $30 \%$ of participants offer half or more, and $20 \%$ of participants offer $40 \%$. However, the distribution of unfair offers differs between the two treatments. In the DNEE treatment, significantly more dictators choose $10 \%$, the minimum amount, than $20 \%$ (47\% of participants vs. $9 \%$ of participants, $p<0.01$, two-tailed Mann-Whitney test). In contrast, in the DEE treatment the fractions of dictators who offer $10 \%$ and $20 \%$ are about the same (28\% and $25 \%$ of participants, respectively). Consistent with our (onesided) hypothesis, and compared with the DNEE treatment, the reduced frequency of

\footnotetext{
${ }^{8}$ Differences in means between DNEE and DEE, and EE and NEE, are in the expected direction but are not statistically significant. However, differences in means between otherwise identical dictator and ultimatum games, DNEE and NEE, and DEE and EE, are statistically significant (in both cases $p<0.01$, one-tailed Mann-Whitney tests.)
} 
offers at the $10 \%$ level in the DEE treatment is statistically significant ( $p=0.028$, one-tail Mann-Whitney test) ${ }^{9}$.

In sum, our data suggest that ex post opportunities for emotion expression can reduce profit-maximizing decisions. This is consistent with our hypothesis, and supports the self-deception model in Konow (2000).

\section{IV.B. Comparing Emotion Expression to Monetary Sanction Effects}

Previous research reveals that dictators are less generous than ultimatum games' proposers who face threats of rejection (see Camerer (2003) for a survey). As is clear from Figure 2, comparing our baseline dictator game data with the ultimatum game data reported in Xiao and Houser (2005) replicates this finding. In particular: (i) more first movers offer $40 \%$ or more in the standard ultimatum game (NEE) than the standard dictator game (DNEE) (68\% and 44\%, $p=0.01$, one-tail Mann-Whitney test); and (ii) significantly fewer minimum offers occur in NEE than DNEE (10\% vs. 47\%, $p<0.001$, one-tail Mann-Whitney test). Moreover, the proportion of minimum offers in NEE is significantly lower than occurs in the dictator game with emotion expression (10\% vs. 25\%, $p=0.04$, two-tail Mann-Whitney test). Therefore, our results suggest that threats of both disapproval and monetary punishment can discourage selfish decisions. In our environment, however, monetary punishment is more effective than the threats of disapproval. On the other hand, although threats of rejection are effective in increasing offers, do so is not efficient as rejection entails loss of the entire surplus.

Combining the data from all four treatments suggests a reason that Xiao and Houser (2005) found no positive effect of emotion expression opportunities on fairness in ultimatum games. Under rejection threats in ultimatum games, the percent of subjects choosing to maximize their monetary payoff decreased from $47 \%$ to $10 \%$. As noted, emotion expression opportunities also discourage subjects from sending minimum

\footnotetext{
${ }^{9}$ It is appropriate in our case to report results of one-sided hypothesis tests, because we developed ex ante the one-tail hypothesis that that emotion expression promotes fairness. Moreover, we noted above that our design is biased against this hypothesis in that we impose restrictions against foul language and threats.
} 
amounts ${ }^{10}$. Thus, the effect of emotion expression opportunities on fairness was masked by the fact that few subjects offer minimum amounts in standard ultimatum games.

\section{IV.C. Messages}

All receivers except one (35/36) in the emotion expression treatment wrote messages to their respective dictators. The emotional content of those messages, as classified by our evaluators, is listed in Table 2. Of 18 total messages written in response to unfair offers, more $(44.4 \%)$ were classified as expressing negative emotions than either positive $(22.2 \%)$ or neutral $(33.3 \%)$. We obtained some evidence that many receivers would have chosen an unfair distribution had they been the dictator, so that they empathized with dictators' selfish choices. It seems not all dictators anticipated this reaction, and some even expressed surprise. One selfish dictator reported ${ }^{11}$ :

Surprisingly, my counterpart said they would have made the same decision, and to enjoy myself. How funny. I don't feel as bad now about my decision. I guess everyone is a little greedy.

Such a reaction makes clear the importance of investigating repeated games in this environment, a pursuit we leave for future research.

\section{Conclusion}

Economists increasingly recognize the importance of emotion in human economic behavior (see, Elster, 1998; Frank, 2002; Loewenstein, 2000; Thaler, 2000). However, our understanding of how emotion, especially emotion expression, affects decisions is still in its early stages ${ }^{12}$. In this paper we reported evidence that opportunities for emotion expression affect economic decisions of both expressers as well as the expressers' targets.

\footnotetext{
${ }^{10}$ A Kruskal-Wallis $k$-sample procedure rejects the hypothesis that there are no differences in median offers among the four (DNEE, DEE, NEE and EE) treatments $(p<0.01)$. Differences can be traced to unfair offers. The null hypothesis that there are no differences in median unfair offers (when receivers are allocated $20 \%$ of the total amount or less) among the four treatments is rejected $(p<0.01)$. However, we cannot reject the hypothesis that the medians among fair offers are the same across the four treatments.

${ }^{11}$ Some subjects voluntarily completed a questionnaire at the conclusion of the experiment.

${ }^{12}$ Scharlemann et al. (2001) study how facial expression can be used as a signal of an intention to cooperate. They find evidence that smiles can increase cooperation among strangers in a one-shot interaction.
} 
Data reported by Xiao and Houser (2005) suggest people are less likely to use costly punishment when they can reveal to their counterparts their feelings regarding the exchange. We argue here, however, that this reduction in costly punishment need not increase unfair decisions. The reason is that people are significantly less likely to make maximally self-interested decisions when ex post reactions are possible.

Our results complement previous studies on nonmonetary informal sanctions (e.g., Masclet et al., 2003; Noussair and Hucker, 2005; Andreoni and Petrie, 2004; Subhasish, 2006), and provide direct evidence that a preference to avoid expression of disapproval can be an important reason why informal sanctions promote fair exchange. Also, our findings are consistent with psychological game theory that incorporates factors such as cognitive dissonance and guilt/shame aversion (see, e.g. Konow, 2000; Rabin, 1994; Akerlof and Dickens 1982) ${ }^{13}$.

Our data suggest that monetary punishment is more effective than informal sanctions in promoting fairness. Nevertheless, monetary punishment can be costly to enforce, and thus is not credible if enforcement costs are sufficiently high. Moreover, sanction threats can be counter-productive (see, e.g., Frey and Oberholzer-Gee, 1997; Gneezy and Rustichini, 2000; Fehr and Falk, 2002, Houser et al., 2008). Our findings argue that allowing ex post written responses can be an efficient alternative means to enforce fair economic exchange.

It is important to emphasize that our design is biased against our hypothesis that emotion expression opportunity promotes fairness in several ways. An important example is that our receivers were asked to avoid using foul or threatening language in their responses to dictators. Previous studies show that forms of messages can matter, and in particular that free-form messages can have stronger effects on behavior than messages with a more restricted content (e.g. Charness and Dufwenberg, 2007). Moreover, both theoretical and empirical studies reveal that cooperation increases when punishment

\footnotetext{
${ }^{13}$ Our results also provide an explanation for the widely replicated finding that reduced "social distance" can promote fairness (see, e.g., Cherry et al, 2002). Perhaps people are more concerned about receiving disapproval as social distance is reduced. At the same time, the opportunity to express disapproval might itself reduce social distance, say by increasing "identifiability" with one's counterpart (e.g., Small and Lowenstein, 2005). This might increase the expected disutility of future disapproval from others and thus promote fairness.
} 
threats are more severe (see, e.g. Becker, 1968; Anderson and Stafford, 2003; Polinsky and Shavell, 2000; Houser et al., 2008).

It is interesting to speculate that this "severity" effect extends to informal punishment and in particular to expressions of disapproval. If so, more extreme forms of disapproval, including threats of violence or foul and degrading insults, might be expected to encourage stronger fairness responses by dictators. Indeed, one study that reports experiments related to our dictator treatments, Ellingsen and Johannesson (2008) does allow extreme forms of disapproval and also finds stronger behavioral effects.

Note that our and Ellingsen and Johannesson's (2008) finding that opportunities for ex post receiver disapproval affects dictator's splits do not conflict with previous studies finding no dictator response to ex ante requests by receivers for a particular split (see, e.g., Charness and Rabin, 2005). A key reason is that requests for more signal selfinterest, and such ex ante signals have been found to have detrimental effects on one's counterpart's generosity (see, e.g., Kuang et al., 2007.) Consequently, a dictator need not be affected by ex ante advice from her receiver to send more, and yet can become more generous in order to avoid ex post disapproval for selfishness. An open and important question is how dictators would respond in an environment including both.

While our focus is disapproval avoidance, approval seeking dictators would also be expected to make more generous offers when ex post messages are possible. While this explanation for our results cannot be entirely ruled out, two points should be kept in mind in this regard. First, no responses on our informal survey of dictators suggested approval seeking as a motive. Second, unlike disapproval avoidance, one who seeks approval desires active praise. Such a preference would be expected to lead dictators to increase frequencies of $40 \%, 50 \%$ or higher offers to the receiver, but we find no affect on decisions in this range.

Finally, our results have important implications for policy makers. In contrast to often uncontrollable emotions, opportunities for emotion expression are relatively more easily controlled within an institutional framework. Thus, mechanism design theorists could exploit connections between ex post complaint processes and ex-ante economic outcomes. For example, a system which facilitates expressions of dissatisfaction might reduce costly consumer boycotts, especially ones stemming from perceptions of unfair 
pricing (see, e.g., Friedman, 1991; or Tyran and Engelmann, 2005). In addition, many have pointed out that ex post messaging in online exchange enables efficiency enhancing reputation formation (e.g., Houser and Wooders, 2006). Our results provide an alternative perspective, in that the possibility of receiving negative messages might alone discourage fraud even in one-shot anonymous exchange. 


\section{Appendix. Instructions}

\section{A. Dictator's instruction in DEE treatment.}

\section{Instructions}

Thank you for coming! You've earned $\$ 5$ for showing up on time. Whatever you earn in the rest of the session will be in addition to this $\$ 5$. The instructions explain how you can make decisions. Please read these instructions carefully! There is no talking at any time during this experiment. If you have a question please raise your hand, and an experimenter will assist you.

You are in Room A. You will be randomly and anonymously paired with someone in Room B. You will never be informed of the identity of this person, either during or after the experiment. Similarly, your matched participant will never be informed about your identity. You are in the role of Divider and your matched participant will be referred to as your Counterpart. You and your Counterpart will participate only once in this decision problem.

This is how the experiment works.

Your task is to divide $\$ 20$ between the two of you. How much money you end up with at the end of the experiment depends on the decisions you make.

\section{Divider (You)}

You will choose a Dividing Rule (described in detail below). A dividing Rule determines how much of $\$ 20$ will go to the Divider (you) and how much will go to your Counterpart.

\section{Dividing Rule}

The possible divisions must be chosen from the table below. You must choose only one of them.

\begin{tabular}{|c|c|}
\hline Possible Dividing Rules & $\begin{array}{l}\text { The rule is } \\
\end{array}$ \\
\hline $\mathbf{A}$ & Divider gets $\mathbf{\$ 1 8}$ and Counterpart gets $\mathbf{\$ 2}$ \\
\hline B & Divider gets $\$ \mathbf{1 6}$ and Counterpart gets $\$ \mathbf{4}$ \\
\hline $\mathbf{C}$ & Divider gets $\mathbf{\$ 1 2}$ and Counterpart gets $\mathbf{\$ 8}$ \\
\hline $\mathbf{D}$ & Divider gets $\mathbf{\$ 1 0}$ and Counterpart gets $\mathbf{\$ 1 0}$ \\
\hline $\mathbf{E}$ & Divider gets $\mathbf{\$ 8}$ and Counterpart gets $\mathbf{\$ 1 2}$ \\
\hline $\mathbf{F}$ & Divider gets $\$ 4$ and Counterpart gets $\$ 16$ \\
\hline $\mathbf{G}$ & Divider gets $\mathbf{\$ 2}$ and Counterpart gets $\mathbf{\$ 1 8}$ \\
\hline
\end{tabular}

\section{Your Counterpart}

After receiving the dividing rule that you chose, your Counterpart can write a short message to you. The message can be anything your Counterpart wants to say to you. Please note: Foul language and threatening messages are not allowed.

\section{Experiment Procedures:}

\section{Step 1: Randomly and anonymously assign counterparts}


There are several envelopes in Room A and Room B. In each envelope in Room A and Room B there is a tag marked with a unique letter. Each envelope looks the same. Everyone in Room A and Room B will randomly pick an envelope. Persons in Room A and Room B who choose the tag with the same letter will be paired.

\section{Step 2: Divider chooses the rule}

The Divider will be given a card where he/she can write down his/her decision. A sample of the decision card is as below:

\section{Divider: (Dividing rule)}

I choose dividing rule That is,

Divider gets $\$$

Counterpart gets $\$$

After finishing the decision, the Divider will also write down the tag letter on the back of the decision cards and put it into his/her envelope. After every Divider has finished, the experimenter will take the envelopes to Room B.

\section{Step 3: The Counterpart receives the Divider's decision.}

The experimenter will give each Divider's envelope to his/her Counterpart according to the tag letter on the card. The Counterpart will see the decision made by the divider. The Counterpart will also be given a blank card where he/she can write a short message to the Divider, and will put both the decision card and the message card into the envelope.

\section{Step 4: Return cards to the Dividers}

After everyone in Room B has finished, the experimenter will take all of the envelopes to Room A and return the envelopes to their Dividers, according to their tag letters. When the Divider gets his/her envelope, he/she will see the message his/her Counterpart wrote, if any.

\section{Step 5: Receive cash payment privately}

Each Divider will be called one by one to the experimenter. When called, the Divider will take his/her decision card, and the experimenter will pay him/her privately. Then the Divider will exit the lab and drop all the other supplies into the box near the monitor room. Everyone in Room B will be paid after all of the Dividers have been paid and have left the lab. When called, the counterpart in Room B will show the experimenter the tag letter and will be paid according to the corresponding decision card.

\section{Throughout this experiment, you won't meet anyone in Room B.}

\section{End of Instructions}

Please raise your hand to indicate that you are finished reading these instructions. When you do, an experimenter will give you a few questions to ensure that you understand how you make decisions. 


\section{B. Receiver's instruction in DEE treatment}

\section{Instructions}

Thank you for coming! You've earned $\$ 5$ for showing up on time. Whatever you earn in the rest of the session will be in addition to this $\$ 5$. The instructions explain how you can make decisions. Please read these instructions carefully! There is no talking at any time during this experiment. If you have a question please raise your hand, and an experimenter will assist you.

You are in Room B. You will be randomly and anonymously paired with someone in Room A. You will never be informed of the identity of this person, either during or after the experiment. Similarly, your matched participant will never be informed about your identity. Your matched participant is in the role of Divider and you will be referred to as Divider's Counterpart. You and your Divider will participate only once in this decision problem.

This is how the experiment works.

The task is to divide $\$ 20$ between the two of you. How much money you end up with at the end of the experiment depends on the decision your Divider makes.

\section{Divider}

The Divider will choose a Dividing Rule (described in detail below). A dividing Rule determines how much of $\$ 20$ will go to the Divider and how much will go to you.

\section{Dividing Rule}

The possible divisions must be chosen from the table below. The Divider must choose only one of them.

\begin{tabular}{|c|l|}
\hline Possible Dividing Rules & \multicolumn{1}{c|}{ The rule is } \\
\hline A & Divider gets \$18 and Counterpart gets \$2 \\
\hline B & Divider gets \$16 and Counterpart gets \$4 \\
\hline C & Divider gets \$12 and Counterpart gets \$8 \\
\hline D & Divider gets \$10 and Counterpart gets \$10 \\
\hline E & Divider gets \$8 and Counterpart gets \$12 \\
\hline F & Divider gets \$4 and Counterpart gets \$16 \\
\hline G & Divider gets \$2 and Counterpart gets \$18 \\
\hline
\end{tabular}

\section{Counterpart (You)}

After receiving the dividing rule that Divider chose, you can write a short message to your Divider. The message can be anything you want to say to the Divider. Please note: Foul language and threatening messages are not allowed.

\section{Experiment Procedures:}

\section{Step 1: Randomly and anonymously assign counterparts}

There are several envelopes in Room A and Room B. In each envelope in Room A and Room B there is a tag marked with a unique letter. Each envelope looks the same. Everyone in Room A and Room B will 
randomly pick an envelope. Persons in Room A and Room B who choose the tag with the same letter will be paired.

\section{Step 2: Divider chooses the rule}

The Divider will be given a card where he/she can write down his/her decision. A sample of the decision card is as below:

Divider: (Dividing rule)
I choose dividing rule___. That is,
Divider gets $\$_{\_}$Counterpart gets $\$_{\_}$

After finishing the decision, the Divider will also write down the tag letter on the back of the decision cards and put it into his/her envelope. After every Divider has finished, the experimenter will take the envelopes to Room B.

\section{Step 3: The Counterpart (You) receives the Divider's decision.}

The experimenter will give each Divider's envelope to his/her Counterpart according to the tag letter on the card. The Counterpart will see the decision made by the divider. The Counterpart will also be given a blank card where he/she can write a short message to the Divider, and will put both the decision card and the message card into the envelope.

\section{Step 4: Return cards to the Dividers}

After everyone in Room B has finished, the experimenter will take all of the envelopes to Room A and return the envelopes to their Dividers, according to their tag letters. When the Divider gets his/her envelope, he/she will see the message his/her Counterpart wrote, if any.

\section{Step 5: Receive cash payment privately}

Each Divider will be called one by one to the experimenter. When called, the Divider will take his/her decision card, and the experimenter will pay him/her privately. Then the Divider will exit the lab and drop all the other supplies into the box near the monitor room. Everyone in Room B will be paid after all of the Dividers have been paid and have left the lab. When called, the counterpart in Room B will show the experimenter the tag letter and will be paid according to the corresponding decision card.

\section{Throughout this experiment, you won't meet any Divider in Room A.}

\section{End of Instructions}

Please raise your hand to indicate that you are finished reading these instructions. When you do, an experimenter will give you a few questions to ensure that you understand how you make decisions. 


\section{REFERENCES}

Akerlof, George A and Dickens, William T. "The Economic Consequence of Cognitive Dissonance", American Economic Review, 1982, 72(3), pp 307-319.

Anderson, L.R. and Stafford, S. L. "Punishment in a Regulatory Setting: Experimental Evidence from the VCM.” Journal of Regulatory Economics, 2003. 24, pp91-110.

Andreoni, James. "Impure Altruism and Donations to Public Goods: A Theory of Warm-Glow Giving?”, Economic Journal, 1990, vol. 100, no. 401, pp. 464-77.

Andreoni, James. "Cooperation in Public Goods Experiments: Kindness or Confusion?" American Economic Review, 1995, vol. 85, no. 4, pp. 891-904.

Andreoni, James and Petrie, Ragan. "Public Goods Experiments Without Confidentiality: A Glimpse Into Fund-Raising." Journal of Public Economics, 2004, 88(7-8), pp1605-1623.

Andreoni, James ; Harbaugh, William and Vesterlund, Lise. "The Carrot or the Stick: Reward, Punishment and Cooperation." American Economic Review, 2003, 93, pp893-902.

Aronson, Elliot. The Social Animal, 7th ed.New York : W.H. Freeman, 1995.

Baumeister, Roy.F., Stillwell, Arlene.M., and Heatherton, Todd.F. "Guilt: An interpersonal approach". Psychological Bulletin, 1994, 115, pp243-267.

Batson, C. Daniel. The Altruism Question: Toward a Social-Psychological Answer. Lawrence Erlbaum Associates, 1991.

Becker, G. "Crime and Punishment: An Economic Approach". The Journal of Political Economy 1968, 76, pp. 169-217.

Bolton, Gary E and Ockenfels, Axel. "ERC: A Theory of Equity, Reciprocity, and Competition." American Economic Review, 2000, 90, pp166-193.

Bowles, Samuel and Gintis, Herbert. "The Economic of Shame and Punishment." Working paper, Santa Fe Institute, 2001.

Camerer, Colin. Behavioral Game Theory: Experiments in Strategic Interaction. Princeton University Press, Princeton, NJ, 2003.

Charness, Gary and Dufwenberg, Martin. "Promises and Partnership," Econometrica, 2006, vol.74(6), pp1879-1601.

Charness, G. and Dufwenberg, M. “ Broken Promises: An Experiment”, 2007 working paper.

Charness, G. and Rabin, M. "Expressed Preferences and Behavior in Experimental Games" Games and Economic Behavior, 2005, 53, pp.151-169.

Cherry, T., Frykblom, P., and Shogren, J. "Hardnose the Dictator." American Economic Review, 2002. 92(4), 1218-1221.

Dickinson, David L. "The Carrot vs. the Stick in Work Team Motivation," Experimental Economics, 2001, 4, pp107-124.

Dana, J., Weber, R. A. and Kuang, J., "Exploiting „,moral wriggle room : Experiments demonstrating an illusory preference for fairness." Economic Theory, 2007, 33(1): 67-80.

Dufwenberg, Martin. "Marital Investment, Time Consistency, and Emotions", Journal of Economic Behavior \& Organization, 2002. 48, pp5-69.

Ellingsen, T. and Johannesson, M. "Anticipated verbal feedback induces pro-social behavior." Evolution and Human Behavior, Forthcoming. 2008. 29(2), 100-105.

Elster, Jon. Alchemies of the Mind: Rationality and the Emotions, Cambridge, 1999.

Elster, Jon. "Emotions and Economic Theory", Journal of Economic Literature, vol XXXVI, 1998, pp, 47-74.

Elster, Jon. "Rationality and the Emotions", The Economic Journal, 1996, 105, 1386-1397.

Fehr, Ernst and Gächter, Simon. "Fairness and Retaliation: The Economics of Reciprocity", Journal of Economic Perspectives, 2000, 14(3), pp159-181.

Fehr, Ernst; Gächter, Simon and Kirchsteiger, Georg. "Reciprocity as a Contract Enforcement Device: Experimental Evidence”, Econometrica, 1997, vol 65 (4), pp833-860.

Fehr, Ernst and Schmidt, Klaus. "A Theory of Fairness, Competition, and Cooperation." 
Quarterly Journal of Economics, 1999, 114, pp817-868.

Fehr, Ernst and Schmidt, Klaus. "Theories of Fairness and Reciprocity - Evidence and Economic Applications", Dewatripont, M., Hansen L. and St. Turnovsky (Eds.), Advances in Economics and Econometrics - 8th World Congress, Econometric Society Monographs, Cambridge, Cambridge University Press, 2002.

Fehr, Ernst and Falk, Armin. "Psychological Foundations of Incentives." European Economic Review,2002, 46, pp 687-724.

Ferraro, Paul J. and Vossler, Christian A. "The Dynamics of Other-regarding Behavior and Confusion: What's Really Going on in Voluntary Contributions Mechanism Experiments?", working paper, 2005.

Festinger, Leon. A theory of cognitive dissonance. Stanford, CA: Stanford University Press, 1957.

Frank, Robert. H. "Cooperation through Emotional Commitment", Evolution and the Capacity for Commitment, ed. Nesse, R. M. (Russell Sage Foundation, NY), 2002, pp57-76.

Friedman, Monroe. "Consumer boycotts: a conceptual framework and research agenda." Journal of Social Issues, 1991, 47, pp149-68.

Frey, Bruno S. and Oberholzer-Gee, Felix. "The Cost of Price Incentives: An Empirical Analysis of Motivation Crowding-Out." American Economic Review, 1997, 87 (4), pp746-755.

Gächter, Simon, and Fehr, Ernst. "Collective Action as a Social Exchange." Journal of Economic Behavior and Organization, 39, 1999, 341-69.

Geanakoplos, John; Pearce David and Stacchetti, Ennio. "Psychological Games and Sequential Rationality", Games and Economic Behavior, 1989, 1, pp60-79.

Gneezy, Uri and Rustichini, Aldo. “A Fine Is A Price.” Journal of Legal Studies, 2000, 29(1), pp1-17.

Güth, Werner; Schmittberger, Rolf and Schwarze, Bernd. "An Experimental Analyses of Ultimatum Bargaining", Journal of Economic Behavior and Organization, 1982, vol. 3, no. 3, 367-88.

Houser, Daniel and Wooders, John. "Reputation in auctions: Theory, and evidence from eBay." Journal of Economics and Management Strategy, forthcoming.

Houser, Daniel ; Xiao, Erte; McCabe, Kevin and Smith, Vernon. "When punishment fails: Research on sanctions, intentions and non-cooperation", Games and Economic Behavior, forthcoming.

Huang, Peter and Wu, Ho-Mou. "More Order without More Law: A Theory of Social Norms and Organizational Cultures", Journal of Law, Economics \& Organization, 1994, 10, pp390406.

Jacob, Goeree and Holt, Charles."Asymmetric Inequality Aversion and Noisy Behavior in Alternating-Offer Bargaining Games”, European Economic Review, vol. 44(4-6), 2000, pp1079-89

Kandel,Eugene, and Lazear, Edward. "Peer Pressure and Partnership", Journal of Political Economy, 1992, 100, pp801-817.

Konow, James. "Fair Share: Accountability and Cognitive Dissonance in Allocation Decisions", American Economic Review, 2000, 90(4), pp. 1072-1091.

Kuang, X.J. Weber, R. and Dana, W. "How effective is advice from interested parties? An experimental test using a pure coordination game". Journal of economic behavior and organization. 2007, 62. pp. 591-604.

Kurzban, Robert and Houser, Daniel. "An experimental investigation of cooperative types in human groups: A complement to evolutionary theory and simulations." Proceedings of the National Academy of Sciences, 102(5), 2005, pp1803-1807.

Loewenstein, George."Emotions in Economic Theory and Economic Behavior," American Economic Review, 2000, Vol. 90(2), pp 426-432.

Masclet, David; Noussair, Charles; Tucker, Steven and Villeval, Marie-Claire. "Monetary 
and Non-monetary Punishment in the Voluntary Contributions Mechanism", American Economic Review, 2003, 93, pp366-380.

Miller,John H.; Butts, Carter and Rode,David. "Communication and Cooperation," Journal of Economic Behavior and Organization, 47 (2002):179--95.

Noussair, Charles and Tucker, Steven. "Combining Monetary and Social Sanctions to Promote Cooperation", Economic Inquiry, 2005, Vol. 43(3), 649-660.

Ostrom, Elinor; Walker,James and Gardner, Roy. "Covenants With and Without a Sword: Self-Governance is Possible." American Political Science Review, 1992, 86, pp 404 - 417.

Rabin, Mathew. "Incorporating Fairness into Game Theory and Economics". American Economic Review. 1993, vol. 83, pp1281-1302.

Rabin, Mathew. "Cognitive Dissonance and Social Change." Journal of Economic Behavior and Organization, 1994, 23(2), pp.177-194.

Rege, Mari and Telle, Kjetil. "The Impact of Social Approval and Framing." Journal of Public Economics, 88(7-8), 2004, 1625-44.

Scharlemann, Jorn W.; Eckel, Catherine; Kacelnik, Alex and Wilson, Rick. "The value of a smile: Game theory with a human face", Journal of Economic Psychology, 2001, Vol 22(5), pp 617-640.

Shavell, Steven. "Law versus Morality as Regulators of Conduct", American Law and Economics Review, 2002, vol. 4, no. 2, pp. 227-57.

Polinsky, A. M. and Shavell, S. "The Economic Theory of Public Enforcement of Law," Journal of Economic Literature, American Economic Association, 2000, 38(1), pp 45-76.

Small, Deborah A. and Loewenstein, George. "The Devil you Know: The Effects of Identifiability on Punishment", Journal of Behavioral Decision Making, 2005,18, pp311-318.

Subhasish, D. "Non-Monetary Sanctions and Behavior in Experimental Coordination Games", working paper

Tangney, J.P., Stuewig, J. and Mashek, D.J. “ Moral Emotions and Moral Behavior”, Annual Review of Psychology, 2007, Vol. 58, pp. 345-372.

Tesser. Abraham and Aschee. John. "Aggression, Love, Conformity, and Other Social Psychological Catastrophes," in Dynamical systems in social psychology. eds: Vallacher, R.R. and Nowak, NY: Academic Press, 1994, pp. 96-109.

Thaler, Richard. "From Homo Economicus to Homo Sapiens," Journal of Economic Perspectives, 2000, Vol. 14(1), pp 133-141.

Tyran, Jean-Robert and Engelmann, Dirk. "To Buy or Not to Buy? An Experimental Study of Consumer Boycotts in Retail Markets" Economica, 2005, 72, 1-16.

Xiao, Erte and Houser, Daniel. "Emotion Expression in Human Punishment Behavior", Proceedings of the National Academy of Sciences, 2005, 102(20), 7398-7401.

Yamagishi, Toshio. "Seriousness of Social Dilemmas and the Provision of a Sanctioning System.” Social Psychology Quarterly, 1988, 51(1), pp32-42.

Yamagishi, Toshio. "The provision of a Sanctioning System as a Public Good." Journal of Personality and Social Psychology. 1986, Vol.51, No. 1, 110-116 
Table 1. Descriptive Statistics

\begin{tabular}{|c|c|c|c|c|}
\hline Treatment & \# of obs. & $\begin{array}{l}\text { Mean Offer } \\
(\% \text { of } \$ 20)\end{array}$ & $\begin{array}{l}\text { Percentage of } \\
50 / 50 \text { Offers }\end{array}$ & $\begin{array}{l}\text { Percentage of } \\
\text { 90/10 Offers }\end{array}$ \\
\hline $\begin{array}{l}\text { Dictator Game } \\
\text { (DNEE) }\end{array}$ & 34 & $\begin{array}{l}26.8 \\
(3.1)\end{array}$ & $\begin{array}{l}26.5 \\
(7.7)\end{array}$ & $\begin{array}{l}47.1 \\
(8.7)\end{array}$ \\
\hline $\begin{array}{l}\text { Dictator Game with } \\
\text { Emotion Expression } \\
\text { (DEE) }\end{array}$ & 36 & $\begin{array}{l}30.3 \\
(2.8)\end{array}$ & $\begin{array}{l}27.8 \\
(7.6)\end{array}$ & $\begin{array}{l}25.0 \\
(7.3)\end{array}$ \\
\hline $\begin{array}{l}\text { Ultimatum Game } \\
\text { (NEE) }\end{array}$ & 62 & $\begin{array}{l}36.9 \\
(2.0)\end{array}$ & $\begin{array}{l}33.9 \\
(6.1)\end{array}$ & $\begin{array}{c}9.7 \\
(3.8)\end{array}$ \\
\hline $\begin{array}{l}\text { Ultimatum Game with } \\
\text { Emotion Expression } \\
\text { (EE) }\end{array}$ & 86 & $\begin{array}{l}39.8 \\
(1.4)\end{array}$ & $\begin{array}{l}37.2 \\
(5.3)\end{array}$ & $\begin{array}{c}4.7 \\
(2.3)\end{array}$ \\
\hline
\end{tabular}

Note: Numbers in the parenthesis are standard errors.

Table 2. Percentages of Receivers and Responders Who Send Messages in DEE and EE Treatments

\begin{tabular}{|c|c|c|c|c|c|c|c|c|}
\hline \multirow{2}{*}{$\begin{array}{l}\text { Offer } \\
(\%)\end{array}$} & \multicolumn{4}{|c|}{ DEE } & \multicolumn{4}{|c|}{ EE } \\
\hline & Positive & Negative & Neutral & Total & Positive & Negative & Neutral & Total \\
\hline$>=50$ & 72.7 & 9.1 & 18.2 & 100.0 & 80.6 & 0.0 & 11.1 & 91.7 \\
\hline 40 & 16.7 & 33.3 & 50.0 & 100.0 & 22.6 & 32.3 & 25.8 & 80.7 \\
\hline 20 & 10.0 & 40.0 & 50.0 & 100.0 & 0.0 & 80.0 & 6.7 & 86.7 \\
\hline 10 & 33.3 & 44.4 & 11.1 & 88.9 & 0.0 & 75.0 & 25.0 & 100.0 \\
\hline Total & & & & 100.0 & & & & 87.2 \\
\hline
\end{tabular}


Table 3. Messages Written When Receiver's Offer is $20 \%$ or $10 \%$

\begin{tabular}{|c|c|c|}
\hline Offer $(\%)$ & Messages & Emotion \\
\hline 20 & $\begin{array}{l}\text { Even though a little more would have been appreciated, thanks for } \\
\text { not giving me } \$ 2 \text {. Enjoy the } \$\end{array}$ & Positive \\
\hline 20 & Should split it 10 and 10. both leave w/ same amount & Neutral \\
\hline 20 & Fair enough & Neutral \\
\hline 20 & I probably would have done the same & Neutral \\
\hline 20 & Pumpkin pie cartwheels edgewise with a side of pancake batter. & Neutral \\
\hline 20 & Thanks for your boundless generosity. & Negative \\
\hline 20 & $\begin{array}{l}\text { How } \$ 4 \text {. Since there was no reason for you to split the money } \\
\text { evenly, I suppose I should be surprised. I wonder though, if you } \\
\text { found someone's wallet, would you only return part of it? If you } \\
\text { decide them like you did today, it must mean that you are only } \\
\text { somewhat hard up for cash. If that's the case, I feel badly for you. } \\
\text { Have a great day. }\end{array}$ & Negative \\
\hline 20 & Thanks for $\$ 2$ more than the minimum & Negative \\
\hline 20 & $\begin{array}{l}\text { Although I would have enjoyed a little bit more than } \$ 4 \text {, I } \\
\text { understand why you chose "B." Thanks for not choosing "A"... I } \\
\text { would have been mad a that, but I'm not as angry now. :- }\end{array}$ & Neutral \\
\hline 20 & $\begin{array}{l}\text { I suppose I don't have to eat again this week. I understand w/e it was } \\
\text { you need must be more important than my sustenance. }\end{array}$ & Negative \\
\hline 10 & Thank you for choosing this dividing role. & Positive \\
\hline 10 & $\begin{array}{l}\text { Thanks for your decision. I would have chosen the same dividing } \\
\text { rule you did. Enjoy your cash }\end{array}$ & Positive \\
\hline 10 & Thanks, you lucky duck! I would have done the same. & Positive \\
\hline 10 & I'd have done it. Why choose anything else? & Neutral \\
\hline 10 & $\begin{array}{l}\text { I'm wondering what I will get. Yes, I know that's what I will exactly } \\
\text { get. Why do they do this kind of experiment anyways! (They are } \\
\text { getting cheaper and cheaper... I can barely make anything here.. I'm } \\
\text { going to starve) }\end{array}$ & Negative \\
\hline
\end{tabular}




\begin{tabular}{|c|c|c|}
\hline Offer $(\%)$ & Messages & Emotion \\
\hline \multirow[t]{3}{*}{10} & $\begin{array}{l}\text { Dear Divider: } \\
\text { What was your first thought when you learned of your position in } \\
\text { this experiment? Do you feel lucky? Are you someone who needed a } \\
\text { break and this was it? Do you feel like this is hilarious and it sucks } \\
\text { to be on the receiving end? Did you feel guilty? Or did you feel } \\
\text { reluctant and hoped I'd understand? Either way just think about it. } \\
\text { You might have made the right decision because I might have } \\
\text { deserved. Or it was just tough luck being me? }\end{array}$ & Negative \\
\hline & Yours truly, & \\
\hline & $\begin{array}{l}\text { Counterpart "A" } \\
\text { P.S. I will never forget you. } \\
\text { P.P.S. No hard feelings. }\end{array}$ & \\
\hline 10 & $\begin{array}{l}\text { I know you're saying "I don't know and I don't care about the other } \\
\text { person," but we all like money, so to know you cut me short is } \\
\text { messed up. I'm not asking for the majority. I'm asking for } \$ 10 / \$ 10 \text {. } \\
\text { If you can change it, please do. If you can't, ... you need to check } \\
\text { your priorities...it's not about the money, it's about sharing what } \\
\text { you have and realizing you're not the center of the world. } \\
\quad \text { - Counterpart C }\end{array}$ & Negative \\
\hline 10 & $\begin{array}{l}\text { Man, what is that? } \$ 2 \ldots \text { when you get } \$ 18 ? \text { You should have split it } \\
\$ 10 / \$ 10 \text { man... }\end{array}$ & Negative \\
\hline
\end{tabular}


Figure 1. Distribution of Dictators' Offers

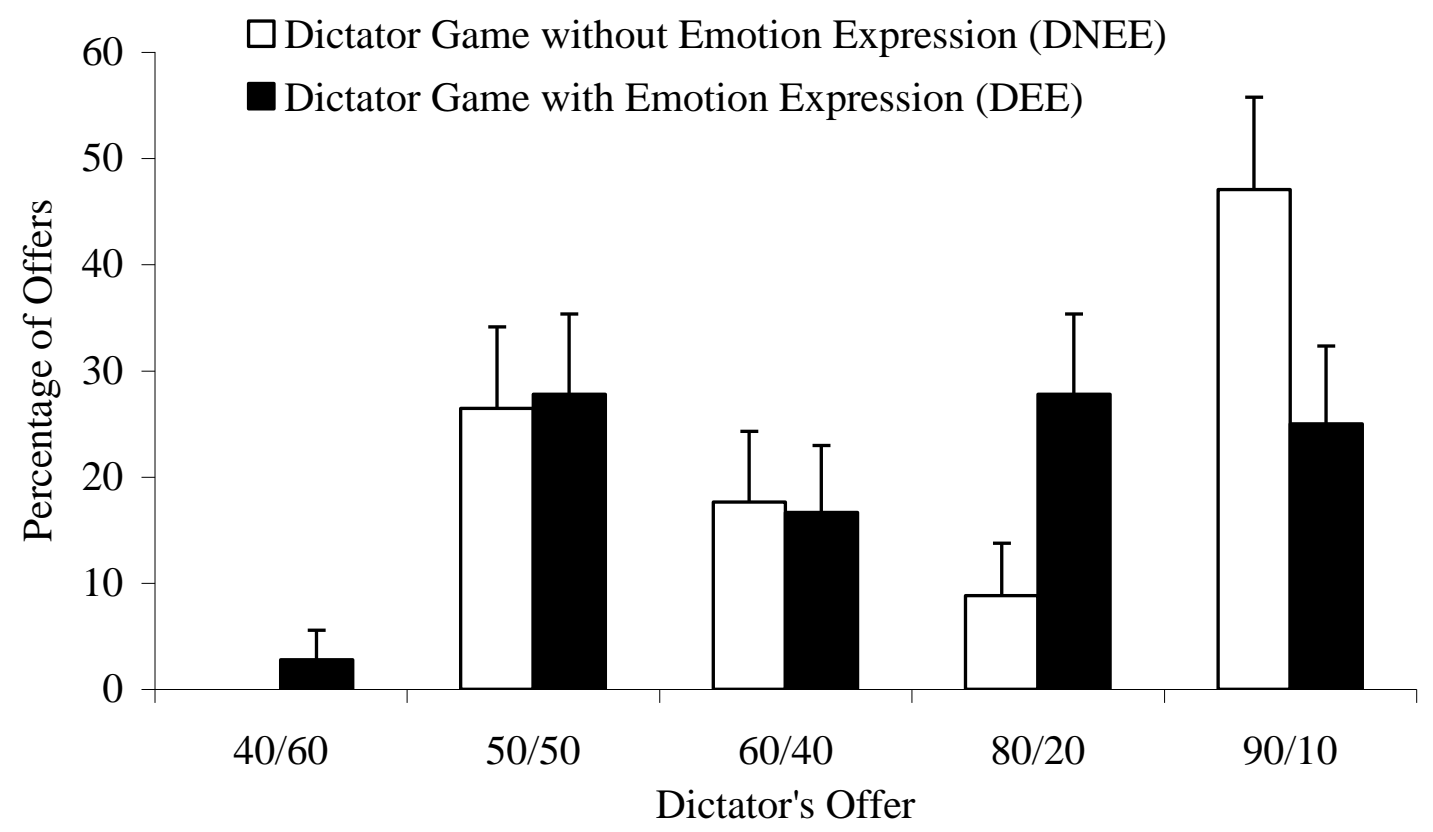

Note: Offers are denoted $\mathrm{X} / \mathrm{Y}$, where $\mathrm{X}$ is the dictator's percentage share, and $\mathrm{Y}$ is the receiver's share.

Figure 2. Distribution of Offers in Standard Dictator and Ultimatum Games

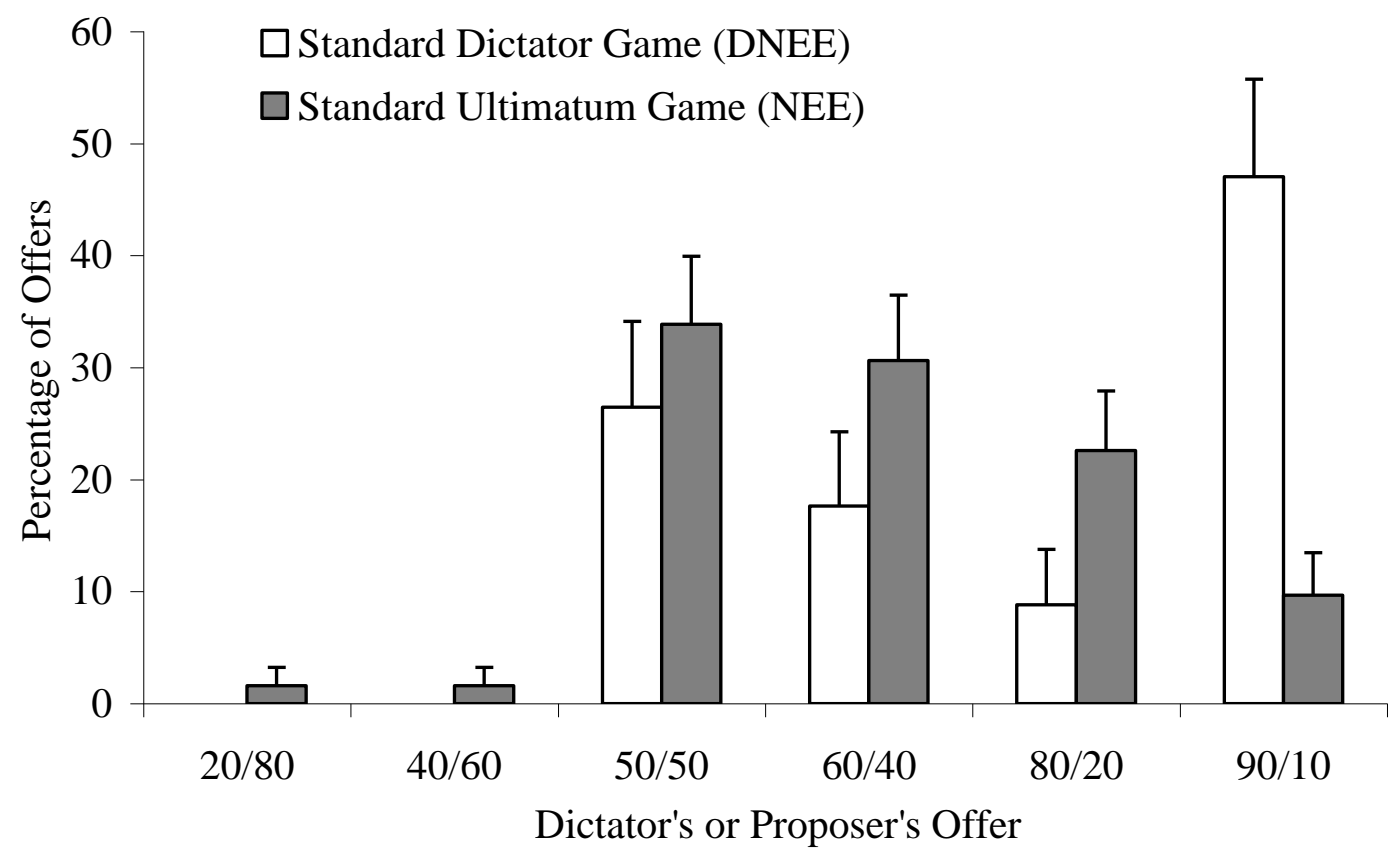

Note: Offers are denoted $\mathrm{X} / \mathrm{Y}$, where $\mathrm{X}$ is the proposer's or dictator's percentage share, and $\mathrm{Y}$ is the responder's or receiver's share. 